\title{
El amor y el instinto sexual en la antropología de Max Scheler
}

\section{Love and sexual instinct in Max Scheler's anthropology}

\author{
Leonardo RoDRíGUEZ DuPLÁ \\ Universidad Complutense de Madrid
}

Recibido: 04-06-2012

Aceptado: 18-01-2013

\section{Resumen}

Este trabajo examina la teoría de la sexualidad elaborada por Max Scheler, tomando para ello como punto de partida su tesis de que el eros es la esencia de la vida. En un primer momento se estudia el "amor sexual", para lo cual se recurre a la teoría de los sentimientos de valor, y más en particular al análisis scheleriano del "apetito". Luego se considera el "instinto sexual" y se expone la crítica de Scheler a la teoría ontogenética de Freud. Por último, se discute la opinión de Scheler acerca de la importancia metafísica del acto sexual humano.

Palabras clave: Scheler, amor sexual, instinto sexual, acto sexual

\begin{abstract}
Starting from Scheler's claim that eros is the essence of life, this paper examines his theory of sexuality. I firstly consider "sexual love", taking into account Scheler's doctrine of value-emotions, particularly his view on "appetite". Then I consider "sexual instinct", putting forward Scheler's criticism of Freud's ontogenetic theory. Lastly I discuss Scheler's view on the metaphysical importance of human sexual intercourse.
\end{abstract}

Keywords: Scheler, sexual love, sexual instinct, sexual intercourse 


\section{Planteamiento}

A lo largo de toda su trayectoria intelectual, Max Scheler ${ }^{1}$ sintió un permanente interés por los problemas de la biología, e incluso llegó a concebir la idea de publicar un estudio sobre los fundamentos filosóficos de esta ciencia. ${ }^{2}$ Aunque este proyecto no llegó a materializarse, sabemos que su propósito era el de elaborar una "biología pura" (GW 15, 195) que enunciara las leyes universales y necesarias de la vida. Enfrentándose a la biología mecanicista de su tiempo, Scheler deseaba mostrar que esas leyes eran irreductibles a los principios de conservación de la mecánica clásica, por ser la vida una realidad primitiva y última. A la vez, estaba persuadido de la unidad fundamental de los fenómenos orgánicos: todos ellos son manifestaciones de la "vida cósmica" (Alleben), atributo metafísico del fundamento primero de la realidad.

La reflexión fenomenológica sobre el hecho de la vida llevó a Scheler a restringir considerablemente el alcance de dos de los más importantes principios de la biología mecanicista: el principio de la lucha por la vida y el de la adaptación al medio. A juicio de Scheler, en el mundo orgánico se registran tanto la tendencia a la cooperación y la solidaridad -mediada por los fenómenos de simpatía-, como la tendencia a la competencia y la lucha por la supervivencia. Pero de estas dos tendencias la primera es la dominante, y tanto más cuanto más amplias sean las unidades orgánicas consideradas. Por otra parte, la relación entre el ser vivo y su medio natural no ha de entenderse en términos de adaptación unidireccional, como si el medio fuera el pie forzado al que ha de acomodarse el organismo, sino que uno y otro son creación de la vida misma en su despliegue incesante. De hecho, el predominio de la tendencia a la adaptación es considerado por Scheler, no una manifestación esencial de la vida, sino un síntoma de decadencia. Estos dos principios de la biología pura -prioridad de la cooperación sobre la lucha y carácter creador de las energías orgánicas-, están íntimamente relacionados con la tesis capital de que la vida es, en su fondo último, “eros" (GW 7, 125 y 133), tendencia a la realización de valores cada vez más elevados. ${ }^{3}$

Ni que decir tiene que la identificación del eros como esencia de la vida ha de tener consecuencias importantes para la antropología filosófica. Es verdad que el propio Scheler limita el alcance de esas consecuencias al advertir, frente a ciertas orientaciones del vitalismo, que el hombre es un ser biológicamente indefinible. En efecto, el hombre es ante todo un ser personal y, como tal, "una cosa que se trasciende a sí misma y a su vida y a toda vida" (GW 2, 293). Pero aunque la doctrina scheleriana del eros no pueda aportar todos los fundamentos teóricos para el desarrollo de la antropología, no es menos cierto que ella constituye, según Scheler, la clave explicativa última de la dimensión vital del ser humano.

El propósito de este trabajo es mostrar que las ideas biológicas de Scheler aportan, en particular, el marco teórico que permite entender su compleja interpretación de la sexualidad humana. En un primer momento expondremos el concepto scheleriano del "amor

\footnotetext{
1 Citaremos siempre a Scheler por los Gesammelte Werke, editados por Maria Scheler y Manfred Frings, con indicación de volumen y página.

2 En dos ocasiones al menos (cf. GW 2, 461 Anm.1 y GW 10,225, Anm.1) anuncia Scheler la próxima aparición de esa obra.

3 Para un desarrollo amplio de las ideas mencionadas en este párrafo, puede verse nuestro reciente trabajo "Las ideas biológicas de Max Scheler", Daimon 7 (2012) 97-115.
} 
sexual”, para lo cual será necesario recalar en la teoría de los sentimientos de valor elaborada por este filósofo, y más concretamente en la función cognoscitiva que atribuye a las formas superiores de la vida emocional. En un segundo paso, presentaremos el modo como el amor sexual se prolonga en el "instinto sexual", engarzando de este modo con la dimensión pulsional de la existencia humana. Por último, discutiremos el modo como Scheler reivindica la importancia metafísica del "acto sexual" humano. Este recorrido por los parajes fundamentales de la doctrina scheleriana de la sexualidad humana nos permitirá comprobar la fuerte cohesión interna del sistema diseñado por este autor en el período intermedio de su producción filosófica.

\section{El amor sexual como especificación del amor vital}

En lugar de "eros" podemos decir también "amor vital”. Esta designación tiene la ventaja de recordarnos que si bien la vida es amor, no todo amor pertenece a la esfera de la vida. Existe también, en efecto, el amor espiritual, el cual se despliega en la esfera personal. ${ }^{4}$ Uno y otro amor tienen en común el ser movimientos dirigidos a valores superiores a los ya encarnados por el objeto amado. En el caso del amor vital, que es el que aquí interesa, los valores a los que apunta el movimiento amoroso son los "valores vitales", que Scheler tiene por irreductibles a los valores del agrado sensible y de lo útil. A los valores vitales los denomina Scheler en ocasiones "valores de lo noble", y señala como ejemplos la salud, el vigor o el poderío que captamos emocionalmente en los organismos que nos rodean o en nuestro propio cuerpo; ejemplos de disvalores de esta esfera serían la languidez, la decadencia, la debilidad.

Teniendo esto en cuenta, la tesis de que la vida, en su fondo último, es eros significa que la entera vida cósmica puede ser descrita como un movimiento ascendente que persigue -en todas sus manifestaciones, por variadas que sean- una meta única: alcanzar cotas cada vez más altas de valor vital. Como se advirtió más arriba, la vida no busca la mera reproducción (Fortpflanzung), si por tal se entiende la repetición de estructuras específicas siempre iguales. La vida busca propagarse, claro que sí, pero busca siempre hacerlo en sentido de una "reproducción elevadora" (Hinaufpflanzung: GW 7, 125; GW 10, 72), suscitando individuos y especies orgánicas cada vez más perfectas desde la óptica del valor vital. El despliegue pluriforme de la vida cósmica sigue siempre una pauta eugenésica, pues su meta verdadera es la mejora de la especie y, llegado el caso, su transformación. ${ }^{5}$

\footnotetext{
4 En la segunda parte de Esencia y formas de la simpatía Scheler presenta el "amor anímico" como una tercera forma de amor irreductible al amor vital y al espiritual. Sin embargo, su explicación no es convincente en este punto, y de hecho el amor anímico es abandonado tácitamente en las obras posteriores de este autor. Sobre esta cuestión puede verse nuestro trabajo "La esencia y las formas del amor según Max Scheler", Anuario Filosófico 45/1 (2012) 69-96.

5 Cierto que al comienzo del ensayo Sobre la vergüenza y el pudor, que vio la luz en el primer volumen de los escritos póstumos de Scheler (cf. GW 10, 65-154, en especial 70ss.), se sostiene que la vida, en sus escalones ínfimos, parece ser un mero proceso reproductivo. También se afirma en ese lugar que el valor vital es directamente proporcional al grado de individuación de los organismos que son portadores de ese valor, de suerte que la eugenesia natural practicada sistemáticamente por la vida
} 
En las especies biológicas en las que se da la diferencia de lo masculino y lo femenino, el amor vital se manifiesta a menudo como "amor sexual" (Geschlechtsliebe). ${ }^{6}$ Según veremos en lo que sigue, la función de esta variante del amor vital es guiar selectivamente el emparejamiento de individuos de distinto sexo con vistas al aumento del valor vital de su descendencia. Y es que la diferenciación de sexos es, según Scheler, una estrategia adoptada por la vida cósmica en aras de su propio ennoblecimiento. Dicha diferenciación no era necesaria para la mera propagación de la vida, ya que la vida puede reproducirse también sin recurrir a ese expediente, como ocurre en el caso de la reproducción por división celular. Más aún, la diferenciación de sexos supone una rémora para el proceso reproductivo como tal, pues lo limita cuantitativamente al no permitir que cada organismo pueda reproducirse por sí solo. De aquí se sigue que la meta que persigue la vida al suscitar la diferencia de sexos no es su mera propagación cuantitativa, sino su mejora cualitativa. El objetivo no es simplemente la perpetuación de las especies orgánicas, sino el surgimiento de individuos que encarnen mayor perfección vital que sus progenitores. Este objetivo no se logra mediante la combinación azarosa de los genotipos individuales, sino merced a la selección del compañero de reproducción operada por el amor vital.

También en la esfera de la afectividad humana se registran fenómenos de amor sexual. Es un hecho muchas veces observado que los seres humanos sienten una especial atracción erótica por individuos del sexo contrario que presentan ciertos caracteres típicos. La atracción a la que nos referimos es de índole específicamente vital, y la comparte el hombre con muchas otras especies animales. No debe confundirse, por tanto, con el amor espiritual que nos inspiran nuestros congéneres en tanto que seres personales. ${ }^{7}$ En consecuencia, por más que nuestro interés se refiera sobre todo al amor sexual humano, los principios movilizados para explicar este fenómeno no serán válidos únicamente en el ámbito humano; más bien, representarán la aplicación a ese ámbito concreto de leyes biológicas de muy amplio alcance.

(salvo en sus formas más elementales) perseguiría precisamente alcanzar grados cada vez más altos de individuación (cf. ibid. 72s.). Pero, en nuestra opinión, estas ideas corresponden a una fase en la que el pensamiento biológico de Scheler no había alcanzado aún su formulación madura, y de hecho no tardaron en ser abandonadas. No podía ser de otro modo, pues si la vida cósmica es una, no puede tener distintas metas (unas veces la mera reproducción, otras el aumento de valor vital). Por otra parte, el pensamiento maduro de Scheler reconoce que la verdadera individuación se da en el plano espiritual y no en el vital, por lo que es lógico que vincule el aumento del valor vital a la "mejora de la especie" y no al grado de individuación de sus miembros.

Las discrepancias apuntadas sugieren que la fecha de composición del estudio sobre la vergüenza ha de ser anterior a la de El formalismo, pese a que Maria Scheler, editora de ambos textos, creyó que eran de la misma época. Nuestra hipótesis explica el hecho sorprendente de que Scheler no llegara a publicar este estudio en vida, pese a que la redacción estaba prácticamente concluida: no lo hizo porque correspondía a una fase ya superada de su pensamiento biológico.

${ }^{6}$ A menudo pero no siempre, pues la diferencia del principio reproductor masculino y el femenino se da también en numerosas plantas. También ellas están animadas por el eros que es el fondo último de la vida, pero sería absurdo atribuirles "amor sexual" en el sentido que a continuación se expone.

7 Entre las múltiples diferencias entre el amor espiritual y el sexual, hay una que conviene recordar en este momento: el primero se refiere al ser amado como individuo en sentido estricto, mientras que el segundo se dirige al amado como portador de un cierto tipo de rasgos vitalmente valiosos. 
Scheler no fue, ni mucho menos, el único pensador de su generación que se ocupó del amor sexual. El tema, que es tan antiguo como la filosofía, ${ }^{8}$ había sido puesto nuevamente sobre el tapete de la discusión por Schopenhauer en la primera mitad del siglo XIX. La doctrina de este autor fue intensamente recibida, provocando reacciones y prolongaciones de diverso signo. En consecuencia, la aportación scheleriana al estudio del amor sexual no venía a llenar un vacío teórico, sino que hubo de situarse entre múltiples doctrinas alternativas, con las que Scheler no dudó en polemizar. A su juicio, las teorías hasta entonces disponibles tenían en común el tergiversar el dato que se trataba de explicar, si bien lo hacían de distintas maneras. En unos casos se cometía el error de espiritualizar el amor sexual, ignorando que es un fenómeno vital, no personal. Es el caso de Sombart o de Grotjahn, cuyas teorías Scheler tilda de "románticas". En el extremo opuesto se situaban aquellos que tendían a naturalizar el amor, entendiéndolo como un derivado genético de fenómenos elementales como el instinto sexual (Schopenhauer) o la libido (Freud). Por último, tampoco faltaban quienes, por desconocer que el amor es un hecho primitivo e irreductible, lo entendían como un compuesto de elementos heterogéneos. Lipps, por ejemplo, veía en el amor sexual una mezcla de instinto sexual y simpatía anímica (cf. GW 7, 202; 10, 119).

En las páginas que siguen expondremos con algún detenimiento la concepción scheleriana del amor sexual. Primero abordaremos la consideración positiva de este fenómeno como sentimiento de valor que guía el emparejamiento sexual con vistas a la mejora de la especie. Luego estudiaremos la relación entre el amor sexual y la vida pulsional humana, en particular su relación con el instinto sexual.

\section{El amor sexual como función cognoscitiva de valores vitales}

Desde una perspectiva sistemática, el amor sexual se encuadra entre los sentimientos vitales. Por eso, si queremos entender adecuadamente la concepción del amor sexual propuesta por Scheler, habremos de dirigir la mirada en primer lugar a su teoría de los sentimientos vitales (Lebensgefühle), concentrándonos en los aspectos de esta teoría relevantes para nuestro propósito.

A diferencia de los estados emocionales ciegos, esta suerte de sentimientos se caracteriza por su intencionalidad, referida siempre a objetos portadores de valor vital. El sentimiento vital puede referirse a la propia vida del sujeto, la cual le aparecerá como ascendente o descendente, como vigorosa o enferma. O puede referirse a la vida ajena, como ocurre en los casos de simpatía vital. O también puede dirigirse a otros elementos de mi entorno (Umwelt) que aparezcan revestidos de algún valor o disvalor vital, es decir, que fomenten de algún modo mi propia vida o la amenacen. Es a esta última función del sentimiento vital a la que debemos prestar especial atención en el presente contexto.

Merced a su carácter intencional, el sentimiento vital capta ventajas y peligros para la propia vida que son inaccesibles a cualquier otra forma de conocimiento, sea representativo o conceptual. En este sentido, los sentimientos vitales constituyen para el organismo "un auténtico sistema de signos" (GW 2,343) que se activa antes de que el provecho o el per-

\footnotetext{
8 Cf. Helmut Kuhn, Liebe. Geschichte eines Begriffs, Kösel, Múnich, 1975.
} 
juicio se consumen, e incluso antes de que exista clara conciencia de la naturaleza de los procesos que los ocasionan. Es esta capacidad de anticiparse espacial y temporalmente lo que lleva a Scheler a describir plásticamente el sentimiento vital como una suerte de "sentimiento a distancia" (Ferngefühl: GW 2, 344; Fernfühlen: GW 15, 203). Una vez activado el sentimiento vital, el organismo reaccionará en consecuencia, aprovechando la ocasión que se le presenta o rehuyendo el peligro. Pero dado que estos impulsos están condicionados por la previa captación emocional del valor o disvalor vital, el sentimiento vital como tal no debe confundirse con las vivencias tendenciales en que normalmente desemboca. ${ }^{9}$

Ejemplos típicos de sentimiento vital son el miedo, el apetito, el asco, la simpatía vital o la vergüenza sexual. Si bien no podemos exponer aquí las sutiles descripciones fenomenológicas de todos estos sentimientos realizadas por Scheler, al menos hemos de referirnos brevemente a su caracterización del apetito ${ }^{10}$, ya que existe una marcada analogía entre este sentimiento y el amor sexual.

En el lenguaje corriente, el término "apetito" (Appetit) suele utilizarse como sinónimo de ganas o de deseo; designa, por tanto, un fenómeno de naturaleza tendencial. Scheler, en cambio, reserva este término para referirse a la función cognoscitiva de naturaleza emocional que capta el "valor nutritivo" (Nährwert) de una sustancia. Este valor ha de ser distinguido, en primer lugar, de las propiedades fácticas de la sustancia que ingiero, sea que me estén inmediatamente dadas (como el sabor dulce o salado, o la temperatura a la que se encuentra), sea que me las revele el análisis de laboratorio. Es sabido que, apoyándose en el análisis químico de los alimentos, el fisiólogo puede explicar científicamente el hecho de que la ingesta de una cierta sustancia sea beneficiosa para determinado organismo. Pero es evidente que la activación del apetito es independiente del dictamen del fisiólogo, y de hecho guía su investigación.

En segundo lugar, el valor captado por el apetito ha de ser distinguido del valor hedónico que aprecio en la comida o la bebida. Cuando saboreo la fruta madura no sólo advierto que es deliciosa (valor hedónico), sino que capto inmediatamente su carácter saludable (valor nutritivo), su admirable encaje con las necesidades inmediatamente vividas de mi organismo: noto que me sienta bien. Pero lo más importante es que el apetito, entendido como función cognoscitiva, no sólo acompaña a la ingesta, sino que también la precede: aprecio el valor orgánico del agua cristalina o del pan tierno sin haberlos probado todavía, y es de hecho la captación previa de ese valor lo que despierta mi deseo de probarlos.

\footnotetext{
${ }^{9}$ Como tampoco debe confundirse con el placer o el dolor sensible. Debido a que muchas veces acompañan a los procesos vitales beneficiosos o nocivos para el organismo, los sentimientos sensibles pueden llegar a convertirse por asociación en síntomas de esos procesos. Pero este hecho no debe llevarnos a ignorar la diferencia entre los sentimientos sensibles y los vitales. Mientras el placer y el dolor sensible son consecuencia e indicio de la estimulación fáctica del organismo, el sentimiento vital anticipa el valor de los posibles estímulos. "Todo el sentido y toda la importancia de estos sentimientos consiste precisamente en que señalan el valor de lo venidero, no el valor de lo ya presente" (GW 2, 343s.). De hecho, la anticipación emocional de un disvalor vital suele tener por consecuencia que la estimulación correspondiente no llegue a producirse.

10 Cf. sobre todo los siguientes pasajes: GW 2, 251-253; 7, 127-128; $10,83-88$ y $118-119$; y $15,202-$ 205.
} 
Lo contrario del apetito es el asco, por ejemplo el que siento ante una pieza de fruta en estado de descomposición o ante el agua estancada que ya verdea. ${ }^{11}$ El asco capta el disvalor vital de esas sustancias, su carácter nocivo para el organismo. En este caso es aún más claro, si cabe, el carácter de pre-sentimiento (Vorgefühl: GW 10,84) de estas funciones emocionales. No necesito ingerir la fruta podrida para saber que me sentará mal; de hecho, el asco, acompañado característicamente de arcadas y ganas de vomitar, me disuadirá de tales experimentos.

En tercer lugar, hemos de distinguir el apetito, en el sentido que Scheler da a esta término, de las vivencias tendenciales a las que con frecuencia aparece asociado, en especial el hambre (Hunger) y las ganas de comer (Esstrieb). ${ }^{12}$ El hambre es descrito por Scheler como un apremio (Drängen) carente de dirección y acompañado de sensaciones orgánicas dolorosas. A diferencia del apetito, el hambre no capta cualidades de valor; ni tampoco tiene su réplica en una vivencia de signo opuesto, como lo es el asco respecto del apetito. Por lo demás, sabemos por experiencia que el apetito y el hambre varían de manera independiente: quien tiene mucho hambre, puede no sentir ningún apetito, por ejemplo porque encuentra repulsivo el alimento que le ofrecen; $y$, a la inversa, cabe sentir apetito pese a no tener hambre, como le ocurre al gourmand que, impasible, engulle un pastel tras otro. Y tampoco hemos de confundir el apetito con lo que hemos denominado ganas de comer. Es verdad que esta última experiencia tendencial posee ya una dirección, aunque todavía vaga: se trata, según Scheler, del deseo genérico de ingerir alimentos. Pero dado que este deseo no se refiere a ninguna comida en particular, no cabe atribuirle la capacidad de discernir el valor orgánico de las distintas sustancias que caracteriza al apetito. En cuanto a los casos en que las ganas de comer se refieren a un alimento en particular, hemos de ver en ellos una consecuencia del apetito, el cual puede activarse, según sabemos, sin la colaboración del hambre.

Veamos ahora cómo los resultados alcanzados mediante el análisis del apetito arrojan luz sobre el fenómeno del amor sexual. La clave consiste en que tanto el apetito como el amor sexual son funciones cognoscitivas que identifican valores vitales sin recurrir para ello a la mediación de vivencias tendenciales. Este paralelismo entre apetito y amor sexual es enunciado claramente por Scheler en su estudio sobre la vergüenza:

El apetito, que puede faltar aunque se tenga el mayor hambre, es para la selección del alimento en función de su valor exactamente lo mismo que el amor sexual para el instinto sexual y de reproducción. [...] Aquí es el sentimiento amoroso, o simplemente la simpatía sexual, la que de antemano sopesa afectivamente el valor de la unión sexual con el individuo en cuestión, unión que posiblemente satisfaría al instinto. (GW 10,85)

$\mathrm{Y}$ en un pasaje posterior del mismo estudio volvemos a encontrar la misma idea:

\footnotetext{
11 Resulta muy llamativo que Aurel Kolnai no cite a Max Scheler en su famoso estudio fenomenológico sobre el asco. Cf. A.Kolnai, "Der Ekel" (1929), ahora en id., Ekel, Hass, Hochmut. Zur Phänomenologie feindlicher Gefühle, Suhrkamp, Frankfurt, 2007.

12 Tomamos estos términos de GW 2, 252. En el pasaje paralelo de GW 10, 85 se mantiene el término Hunger para el hambre, pero se introduce el infinitivo sustantivado Hungern para las ganas de comer.
} 
Pues al igual que el "apetito" es [...] en la esfera de la nutrición un pre-sentimiento, completamente independiente del "hambre", del valor orgánico de los alimentos [...], y no una reacción al alimento ya elegido -es decir, una estimación anímica previa de lo que debe llegar a la boca-, el amor sexual es un pre-sentimiento que guía la percepción interesada de los individuos (destacándolos de la multitud de los individuos sensiblemente "perceptibles") y capta las mejores y más nobles cualidades para la reproducción. (GW 10, 119)

La analogía del amor y el apetito proporciona a Scheler un fuerte argumento contra las teorías naturalistas del amor vital. Dado que esta suerte de amor es un sentimiento que capta cualidades de valor y que dicha captación es la base indispensable sobre la que luego pueden constituirse vivencias tendenciales dirigidas a objetos portadores de esas cualidades, debe rechazarse toda concepción del amor vital que lo explique como un derivado del deseo sexual. Sobre este punto volveremos enseguida. Por ahora baste con señalar que, a juicio de Scheler, entender el amor vital como "libido sublimada" es tan disparatado como entender el apetito como "hambre sublimada" (cf. GW 7, 125).

Para comprobar que tampoco las interpretaciones espiritualistas hacen justicia a la esencia del amor vital, basta con dirigir la mirada al tipo de valores anticipados emocionalmente por ese sentimiento. Sabemos que en las especies animales bisexuadas el amor sexual, como manifestación que es del eros universal, guía el emparejamiento de individuos de distinto sexo con vistas a la mejora de la especie. Esta función la desempeña el amor vital anticipando "las mejores combinaciones posibles de valores hereditarios" (GW 7, 125). La tarea encomendada al amor vital consistirá, por tanto, en identificar a los individuos del otro sexo cuyos valores vitales mejor se complementen con los propios. Como los valores que cada individuo aporta son distintos, también será distinta la solución propuesta en cada caso al problema del emparejamiento. Pero es de la mayor importancia advertir que, según Scheler, la selección operada por el amor vital no es absolutamente individualizadora, sino que se limita a identificar a los individuos del otro sexo portadores del tipo de valor que se complementa felizmente con el propio.

Según esto, nada impide que se ame con amor sexual a varios seres del sexo opuesto, incluso a muchos, ya que el objeto amado no es aquí el individuo como tal, sino el ejemplar típico, es decir, el portador de una cierta clase de valores vitales. ${ }^{13}$ Bien es verdad que, debido a la gran intensidad que puede revestir la pasión amorosa, el carácter no individualizador del amor sexual se pasa a menudo por alto. ${ }^{14} \mathrm{El}$ sentimiento amoroso se concentra entonces en un único individuo, con exclusión del resto. Pero, de acuerdo con la doctrina de Scheler, esta aparente exclusividad ha de explicarse por una de estas dos causas: o se da el hecho contingente de que en el horizonte vital del amante haya un único individuo que presente los

\footnotetext{
13 De nuevo resulta útil la analogía con el apetito. Por ejemplo, el aspecto apetitoso de la pirámide de naranjas que el frutero ha colocado en el mostrador despierta en mí el deseo de comprar unas cuantas y comerme una cualquiera de ellas. Incluso si soy particularmente exigente e insisto en elegirlas una a una, lo haré seleccionando las de determinado tipo y rechazando las restantes.

14 Curiosamente, el propio Scheler incurre en una ocasión en este error. Al criticar la concepción romántica del amor sexual alude a "esa exclusividad instintiva que es producida por el genuino amor vital" (GW 7, 124). Sin duda se trata de un lapsus, ya que esta idea es incompatible con la distinción scheleriana de amor sexual y amor espiritual, como se expone a continuación.
} 
rasgos típicos capaces de despertar su amor sexual; o bien ocurre que el amor en cuestión no es puramente sexual, sino que está amalgamado con el amor personal. Precisamente el error capital de las interpretaciones espiritualistas del amor sexual consiste en haber ignorado que este género de amor es esencialmente distinto del amor personal, que por ser de naturaleza espiritual es el único que se refiere al individuo como tal. Esta última tesis la enuncia Scheler con toda claridad en el ensayo sobre la vergüenza:

El amor sexual es [...] una clase y una cualidad especial del amor mismo que, por ello y sólo por ello, puede ser "satisfecho" o "no satisfecho" ["erfüllt" oder "nicht erfüllt"] por personas de ciertas cualidades de valor. No decimos que -en tanto sólo se tome en consideración el mero amor sexual vital, la "pasión amorosa"- para cada individuo resulte elegido sólo un individuo. Esta individualización plena es sólo un rendimiento posible de una forma superior y más espiritual del amor, la cual es independiente del entero ámbito del sentimiento amoroso vital -y por tanto también del amor sexual-. (GW 10, 118s.)

Que el amor específicamente sexual no es individualizador, parece confirmarlo el hecho, tantas veces observado, de que cada ser humano se sienta atraído eróticamente por un determinado tipo de congéneres suyos del sexo opuesto. ${ }^{15}$ Pero también los datos de la antropología cultural abonan, a juicio de Scheler, la misma hipótesis. En las culturas en las que no se reconoce lo bastante la condición personal -y por tanto estrictamente individualdel ser humano, la elección matrimonial se atiene a criterios biológicos, con vistas a la reproducción. Tácito refiere que las mujeres germanas veían en el marido, no al individuo, sino al padre de sus hijos (cf. GW 7, 183). Y es comprensible también que en la cultura tradicional japonesa, que entendía al individuo como un mosaico de rasgos y tendencias vitales heredadas de los antepasados, la elección matrimonial la determinaran los padres, pues ellos estaban en condiciones de elegir, entre los candidatos posibles, a aquellos que mejor encarnaran los valores vitales preferidos por la propia estirpe desde tiempos inmemoriales (cf. 10, 375s.). ${ }^{16}$ Mencionemos, por último, la conexión establecida por Scheler entre la práctica de la poligamia y el desconocimiento de la condición personal de la mujer. El fundamento metafísico de la monogamia es el reconocimiento de la irrepetible individualidad de los dos cónyuges, la cual explica la exclusividad propia del amor conyugal. Esta individualidad sólo está dada donde el ser amado es visto como persona. En cambio, cuando a la mujer se le niega la posesión de un alma personal, la mujer es reducida a una constelación de valores vitales que ella puede compartir con muchas otras, de suerte que no habría motivo justificado para oponerse a la poligamia (cf. GW 7, 184).

15 Como ya se indicó, este aspecto de la preferencia sexual ha sido muy subrayado por Schopenhauer. Scheler está de acuerdo con él en este punto, si bien rechaza la interpretación naturalista del amor sexual preconizada en los apéndices a El mundo como voluntad y como representación.

16 El psicoanálisis ha destacado a menudo que los hijos, llegados a su vida sexual adulta, muestran a menudo las mismas preferencias que el padre, mientras que las niñas reproducen las de la madre. Scheler acepta este hecho, pero no lo retrotrae a experiencias sexuales de la infancia, sino que defiende la transmisión hereditaria de las preferencias eróticas de generación en generación. 


\section{Amor sexual e instinto sexual}

Una vez expuesta la peculiaridad del amor sexual, consideremos el modo como este sentimiento engarza con la dimensión pulsional de la vida humana, en particular con el instinto sexual. De acuerdo con la doctrina sobre el origen de las pulsiones humanas bosquejada por Scheler en sus Problemas de sociología del conocimiento (GW 8, 15-190, esp. 49ss.), existen en el hombre tres pulsiones originarias: la sexual y de reproducción, que está al servicio de la especie; la de poder, que sirve por igual al individuo y a la colectividad; y la de nutrición, dirigida esencialmente a la conservación del individuo. De estas tres pulsiones básicas brotan todas las pulsiones especiales, en parte mediante procesos de diferenciación que se registran en la esfera psicovital, en parte mediante el enlace de la vida pulsional con elementos de naturaleza espiritual. Marx sostenía que, de las pulsiones originarias, la fundamental es la de nutrición, mientras que Nietzsche atribuía la prelación a la pulsión de poder. Scheler, en cambio, proponía una concepción dinámica de las pulsiones, de acuerdo con la cual en cada fase del desarrollo vital predomina una de las pulsiones originarias; y aplicaba este modelo dinámico a su propia teoría de la cultura, la cual explica el cambio social atendiendo tanto a factores espirituales (como la religión, la ciencia, el arte o el derecho) cuanto a factores reales (es decir, los cambiantes sistemas pulsionales derivados de las tres pulsiones básicas).

La teoría scheleriana de las pulsiones no se limita a reivindicar para la pulsión sexual una importancia vital y cultural similar a la que poseen las otras dos pulsiones originales, sino que le atribuye una función especialmente destacada en atención a su estrecha colaboración con el amor vital. No cabe duda de que en este punto Scheler se muestra coherente con sus ideas biológicas; pues si es verdad que todas las pulsiones son manifestaciones e instrumentos de la vida, también lo es que el eros es la esencia misma del proceso vital, su verdadero "punto de ignición" (GW 7, 118), de suerte que el enlace de la esfera sexual con el eros otorga a la pulsión sexual y de reproducción la primacía en el sistema de las pulsiones humanas. ${ }^{17}$

Este subrayado de la importancia de la pulsión sexual parece sugerir un claro parentesco con la antropología de Freud. Veremos en seguida que esta impresión es engañosa. En todo caso, la comparación con el psicoanálisis no es ni mucho menos inútil; antes bien, el modo como Scheler concibe el complejo entramado de las pulsiones sexuales y su colaboración con las distintas formas del amor destaca con especial claridad sobre el telón de fondo de su crítica del reduccionismo naturalista postulado por Freud (cf. GW 7, 177-179 y sobre todo 195-208). 18

Conviene recordar que, en opinión del fundador del psicoanálisis, tanto el instinto sexual como el amor son derivados genéticos de la libido. Freud no cree que la libido sea una tendencia innata, sino que se adquiere en una fase muy temprana de la vida del recién

\footnotetext{
17 Esta primacía se da a conocer en el hecho de que al decaer la pulsión sexual -por ejemplo, a consecuencia del envejecimiento del organismo-, se produce también una involución o decaimiento de los demás sistemas pulsionales. Scheler llega a sostener que la pulsión sexual es, en este sentido, "fundante" respecto a las otras pulsiones (cf. GW 7, 203).

18 Cf. A. Lambertino, "Scheler und die psychoanalytische Freudsche Theorie", en G.Pfafferott (Hg.), Vom Umsturz der Werte in der modernen Gesellschaft, Bonn, 1997, pp. 148-164.
} 
nacido después de que éste haya experimentado sensaciones de placer provocadas por la excitación casual de las zonas erógenas de su organismo (que no coinciden con las de la vida adulta). La libido no sería otra cosa que el deseo de volver a experimentar ese tipo de sensaciones placenteras. Por otra parte, la libido no debe confundirse con el instinto sexual, que es el fruto de un largo y complicado proceso de construcción psíquica que sólo llega a término en una fase muy posterior de la evolución individual: la pubertad. De hecho, el instinto sexual -que en sentido estricto es una pulsión orientada ya al otro sexo- no llega a ser desarrollado por todos los individuos, como demuestra fehacientemente el amplio catálogo de las perversiones sexuales. Como es sabido, Freud no entiende las perversiones como desviaciones de un instinto sexual ya constituido, sino como fijaciones en fases previas del normal desarrollo infantil de la libido; y explica numerosas formas de neurosis precisamente como resultado de este tipo de estancamientos evolutivos. En el caso más frecuente, sin embargo, la libido termina encontrando su objeto en los individuos del otro sexo, con lo cual queda constituido el instinto sexual propiamente dicho. Esto sucede en la pubertad, coincidiendo con la desaparición de las sensaciones ligadas a las zonas erógenas de la infancia y la concentración de las sensaciones sexuales placenteras en los órganos que sirven a la reproducción. Mencionemos, para terminar este rápido bosquejo, que a juicio de Freud también las distintas formas del amor se originan a partir de la libido. En la descripción psicoanalítica del proceso que da origen al amor desempeñan un papel decisivo los conceptos de represión y sublimación. No nos detendremos a exponerlos, puesto que ahora nos interesan únicamente los conceptos de libido e instinto sexual.

La minuciosa crítica de Scheler a esta teoría ontogenética comienza por advertir que la hipótesis freudiana acerca del origen de la libido es claramente deudora de la "teoría empirista del desear". Esta teoría cuenta con numerosos presupuestos erróneos, agudamente denunciados por Scheler en El formalismo (cf. GW 2, 138ss.). La psicología empirista explica los hechos tendenciales más básicos -pensemos por ejemplo en el hambre del lactantecomo resultado mecánico de un proceso asociativo. Al contacto con el pecho de la madre, los labios del niño realizan un movimiento reflejo de succión que hace fluir en su boca y en su estómago la leche materna. Esta experiencia resulta placentera, puesto que elimina el previo estado de displacer orgánico. Tras repetirse a menudo esta secuencia, no tarda en establecerse en el psiquismo del niño una firme asociación entre la succión del pecho materno y las sensaciones de placer tantas veces experimentadas. Surge de este modo, por vez primera, el hambre propiamente dicho (Hungern), que no es otra cosa que el deseo de gozar nuevamente del placer que proporciona el alimento.

La concepción empirista presupone que toda vivencia concreta de orden tendencial se funda en una representación. Si se admite el supuesto de que no se puede desear aquello de lo que no se tiene noticia, resulta lógico afirmar que el niño no sentirá ganas de comer en tanto no experimente el placer que acompaña al alivio de su malestar orgánico y lo asocie a la succión del alimento. Pero precisamente este supuesto tan básico de la psicología empirista será el blanco principal de la crítica de Scheler, quien defenderá que el hambre -entendido como ganas de comer y no sólo como malestar orgánico- es un hecho primitivo e irreductible que pertenece al equipamiento original de la naturaleza humana. Si la psicología asociacionista ha pasado por alto esta verdad, ello se debe a que ha ignorado que en todo deseo maduro cabe distinguir dos aspectos: la orientación a valores de determinado orden y 
la representación de objetos que, por portar esos valores, son capaces de satisfacer el deseo. Scheler no sostiene el absurdo de que el niño nazca sabiendo ya que el alimento materno le proporcionará satisfacción, y por tanto deseando ese objeto concreto. Lo que sostiene es que el niño está innatamente orientado a los valores vitales encarnados por el alimento, y que sólo gracias a ello encuentra satisfacción en ese objeto y llega a desearlo conscientemente. La mera orientación a valores es, por tanto, la forma más primitiva del deseo, y es ella la que está dada con independencia de toda experiencia sensible y de toda representación de objetos.

Los pormenores de la teoría scheleriana del tender están expuestos en los pasajes relevantes de El formalismo (cf. sobre todo el final de la primera sección de la obra: GW 2, 5164). Scheler aporta en ese lugar descripciones fenomenológicas de vivencias tendenciales que, pese a no incluir la representación icónica de un objeto, poseen una indudable dirección a valores; sólo esta dirección previa explica los fenómenos de cumplimiento (Erfüllungsphänomene) que experimenta quien finalmente llega a identificar el bien al que, sin él saberlo, aspiraba desde el principio. Pero, dado que exponer esta teoría del tender sería prolijo, nos limitaremos aquí a observar que la hipótesis de la orientación axiológica del tender es coherente con las ideas biológicas de Scheler. En efecto, si se tiene presente que para este autor la entera esfera pulsional del hombre es un complejo instrumento al servicio de la vida cósmica, y que la vida, en su fondo último, es eros, amor referido a valores vitales cada vez más elevados, se entiende sin dificultad en el marco de esta teoría que todo instinto y todo deseo esté nativamente orientado a valores. ${ }^{19}$ Como, por otra parte, el acceso originario al mundo de los valores es de naturaleza emocional, lo dicho supone que toda vivencia tendencial colabora necesariamente con sentimientos de valor. Esta última tesis ha de serle familiar al lector, pues la hemos encontrado anteriormente ejemplificada en un caso concreto: precisamente el análisis scheleriano del hambre - entendido, no como apremio ciego, sino como ganas de comer-. Vimos, en efecto, que el hambre colabora estrechamente con el "apetito", sentimiento que capta el "valor nutritivo" de los alimentos.

Pudiera parecer que en los últimos párrafos nos hemos apartado demasiado de nuestro itinerario. En realidad, nuestro excurso sobre la teoría empirista del tender nos sitúa en condiciones de entender los motivos por los que Scheler rechaza la concepción freudiana de la libido, así como la teoría alternativa con la que pretende reemplazarla. La analogía con el caso del hambre resultará iluminadora en este punto.

A juicio de Scheler, la libido no es un deseo complejo, construido a partir del material que aportan las sensaciones de placer sexual, sino una tendencia simple e innata. El que ciertas estimulaciones sensibles resulten placenteras en las fases más tempranas de la vida humana se debe precisamente a que el niño cuenta de antemano, como parte de su equipamiento biológico original, con esa tendencia básica de orden sexual. ${ }^{20}$ Cierto que la libido,

\footnotetext{
19 Esto se refiere a deseos vitales; pero vale mutatis mutandis para los deseos espirituales. La diferencia es que en este último caso la dirección axiológica la marca la Gesinnung. Para este último concepto véase la parte tercera de El formalismo.

20 También en este punto se registra una notable evolución en el pensamiento de Scheler. En su ensayo sobre la vergüenza todavía definía imprecisamente la libido como un "tender periférico-sensible dirigido al cosquilleo de la delicia sexual" (GW 11,117), mientras que en el tratado sobre la simpatía negará que las sensaciones placenteras que acompañan a la estimulación de las zonas erógenas sean el
} 
al igual que el hambre del recién nacido, es ciega en el sentido de que no contiene una representación icónica (Bildvorstellung) del objeto capaz de satisfacerla; pero posee desde el principio una orientación precisa a cierto tipo de valores vitales. En opinión de Scheler, por tanto, la libido no es otra cosa que la forma más primitiva del "instinto sexual" (Geschlechtstrieb), es decir, la manifestación primera de la más fundamental de las tres pulsiones originarias antes distinguidas. Y del mismo modo que el deseo de comer presupone el apetito, como sentimiento que capta el valor nutritivo de las cosas y de este modo recorta el ámbito de objetos a los que se dirige ese deseo, la libido está íntimamente ligada al amor sexual y por tanto orientada a limine a los valores vitales del otro sexo (Werte der Andergeschlechtlichkeit). ${ }^{21}$

A diferencia de la libido, el instinto sexual maduro se dirige conscientemente a los individuos del otro sexo, pero lo hace de manera genérica e indiscriminada (wahllos). Puede presentar grandes diferencias de intensidad, pero no es capaz, por sí solo, de seleccionar su objeto. Esta función discriminadora corresponde al amor sexual, que identifica a los individuos portadores de valores vitales adecuados a la mejora de la especie y con ello, en el caso más favorable, encauza el deseo. Scheler afirma de manera muy plástica que el instinto sexual es una "técnica del eros" (GW 7, 118), un mecanismo que persigue únicamente la reproducción de la especie, pero que, subordinado al amor sexual, sirve a fines vitales más elevados.

Como sabemos, esta colaboración del amor con el instinto sexual es análoga a la que se da entre el apetito y el hambre. Vimos que la falta de apetito pone freno a las ganas de comer y el asco incluso hace imposible la ingesta del alimento, por mucho hambre que se tenga. Parecidamente, la completa ausencia de amor bloquea la realización del acto sexual, por intenso que sea el deseo. Al mínimo de amor sexual requerido - al menos en una de las partes- para que se realice el acto sexual lo denomina Scheler "simpatía sexual" (GW 7, 128; $10,118-120)$. En el vocabulario de Scheler, el término simpatía designa dos funciones emocionales distintas: el acceso cognoscitivo a las vivencias psíquicas ajenas (como la pena que siente otra persona) y la subsiguiente reacción emocional propia (por ejemplo, la compasión). En el caso que ahora nos ocupa, el de la simpatía específicamente sexual, el sujeto no sólo accede a las vivencias de una persona del otro sexo y reacciona ante ellas (como le ocurre al hombre que se compadece del dolor de una mujer que acaba de sufrir una desgracia, pero se compadece de esa mujer exactamente igual que se compadecería de la desgracia de

objeto de la libido (GW 7, 198: "ningún tender se dirige de suyo a la realización de sensaciones, sino que todo tender se dirige a contenidos cuya realización, eso sí, puede estar acompañada de tales sensaciones"). Este detalle parece confirmar nuestra datación relativamente temprana del citado ensayo (cf. nota 2).

21 Esta opinión contrasta vivamente con las posiciones actuales (pensemos, por ejemplo, en la teoría de la sexualidad elaborada por Judith Butler) que retrotraen la orientación heterosexual mayoritaria al influjo de factores de orden cultural, tan poderosos como contingentes. Aunque no podemos entrar aquí en esta discusión, debemos destacar al menos que la opinión de Scheler acerca del carácter natural y no meramente cultural de la heterosexualidad humana es coherente con el conjunto de sus ideas biológicas: la libido es una manifestación de la vida, y ésta es en su fondo último amor vital, tendencia a la reproducción elevadora (Hinaufpflanzung), la cual supone en la especie humana la diferenciación de sexos. Obsérvese, sin embargo, que lo dicho se refiere únicamente a la dimensión vital del ser humano, y por tanto deja intacto el problema del amor estrictamente personal. 
un hombre), sino que su simpatía ha de referirse a "diferencias de las vivencias y sus especies erigidas sobre la distinción sexual" (GW 10, 119s.). Aunque Scheler no se detiene a explicar este extremo, parece claro que, a su juicio, las vivencias ajenas a las que accedo mediante los fenómenos de simpatía son vivencias sexuadas, vivencias que llevan desde el principio el sello de la masculinidad o la feminidad. Con frecuencia desatendemos esta diferencia, pero otras veces el sentimiento de simpatía se refiere precisamente a ella, y entonces estamos ante fenómenos de simpatía sexual.22

Mencionemos, para terminar este apartado, que el instinto sexual (sea en la forma primitiva de la libido, sea en la forma madura del deseo) no es la única manifestación de la pulsión sexual humana. El sistema de tendencias e instintos derivados de esa pulsión original incluye asimismo, en el caso de la mujer, el "instinto de reproducción" (Fortpflanzungstrieb). Más aún: el instinto sexual está subordinado en ella al instinto de reproducción, de suerte que la activación del primero presupone la activación del segundo. En el hombre, en cambio, no se registra un instinto de reproducción, sino que la tendencia a la procreación adopta la forma de un deseo consciente. Tampoco se da en el varón, pero sí en la mujer, el "instinto de cuidado de la prole" (Instinkt der Brutpflege), que en realidad es una modificación del instinto de reproducción, "una simple prolongación de la efícacia del instinto de reproducción, el cual es ya necesario para que tenga lugar la concepción y para que se lleve a término el embarazo" (GW 10,117s.).

\section{El acto sexual y su importancia metafísica}

La teoría del amor vital y del instinto sexual expuesta en las páginas precedentes permite entender que Scheler, siempre atento a los fenómenos de orden cultural, reivindique decididamente el significado metafísico del acto sexual frente a la depreciación que éste sufre en la cultura occidental moderna. Dicha depreciación no es casual. La cosmovisión natural del hombre moderno está troquelada por la concepción mecanicista de la naturaleza, la cual desconoce la esencia irreductible de la vida y de los valores vitales. ${ }^{23}$ Dada la conexión entre vida y pulsión sexual antes expuesta, no es de extrañar que la tergiversación mecanicista de los fenómenos orgánicos se traduzca en una concepción errónea de la sexualidad humana, con alguna de cuyas variantes ya nos hemos encontrado con anterioridad.

El ethos burgués moderno entiende la esencia del acto sexual a partir de los fines a que ese acto presuntamente sirve, que no son otros que el placer y la reproducción. Según Scheler, el origen histórico de este prejuicio está en la antigua moral judía, la cual se ha perpetuado eficazmente, al menos en este punto, en la moral cristiana. ${ }^{24}$ El matrimonio y la

\footnotetext{
22 Scheler ilustra su opinión de que sin este tipo de simpatía (expresión mínima del amor) no es posible el acto sexual aduciendo el caso del misógino que, por no haber recibido afecto materno en la infancia, es incapaz de empatizar con las mujeres y por ello se ve obstaculizado en el normal desarrollo de su vida sexual (cf. GW 10, 120).

23 Cf. nuestro trabajo "Las ideas biológicas de Max Scheler", Daimon 7 (2012) 97-115.

24 Debe tenderse en cuenta que las páginas de Esencia y formas de la simpatía en las que Scheler expone este parecer (cf. GW 7, 118ss.) fueron añadidas a la segunda edición de esta obra, publicada en 1923. Para entonces, Scheler ya polemizaba abiertamente con la fe católica que antes profesara y que
} 
prostitución, entendidos como instituciones sociales específicamente burguesas, son una consecuencia de esa concepción finalista de la sexualidad. Ahora bien, este modo de ver las cosas no sólo ignora la verdadera esencia de la sexualidad, sino que comporta una grave devaluación de esta dimensión de la existencia humana. Allí donde el acto sexual persigue alguno de los fines indicados, el otro ser humano queda reducido a la condición de mero medio, de mero instrumento para la satisfacción de los propios deseos, se trate del deseo de placer o del deseo de tener descendencia. Para colmo, la mentalidad burguesa es proclive, en su política matrimonial, a ignorar los derechos del amor sexual, sacrificando en aras del estatus social la elección erótica guiada por los sentimientos. Al proceder de este modo, se perpetra una auténtica subversión de los valores: se desconoce que los valores vitales son superiores a los del bienestar sensible, y que por tanto sólo pueden ser legítimamente sacrificados en aras de valores espirituales. Esta última consecuencia era en realidad inevitable, dado que, como queda dicho, la moderna cosmovisión burguesa desconoce la esencia y el valor de la vida.

Frente a esta concepción finalista, Scheler alega en primer lugar que

el acto sexual como tal no pertenece a lo que se conoce como acciones teleológicas (Zweckhandlungen), sino que representa una acción expresiva (Ausdruckshandlung), la cual no se distingue esencialmente de las diversas acciones que expresan la ternura y el amor, como el beso, la caricia, etc. (GW 7, 118)

La tesis de Scheler es, por tanto, que en el acto sexual encuentra su expresión natural el amor específicamente sexual, es decir, la función emocional que en las especies orgánicas que presentan diferenciación de sexos guía el emparejamiento con vistas al aumento del valor vital. Es importante advertir que, al defender esta tesis, Scheler es perfectamente coherente con sus ideas biológicas. Hemos visto, en efecto, que a su juicio el instinto sexual no es sino "una técnica del eros" (GW 7, 118), de ese amor vital que constituye la esencia última de la vida (GW 7, 133) y que en los animales bisexuados se manifiesta como amor sexual. Y si el instinto sexual está esencialmente subordinado a la vida, de la cual es instrumento, resulta lógico afirmar -en el plano ontológico- que el acto sexual prolonga el amor que está en su origen; y criticar -en el plano moral- los prejuicios sociales burgueses que dificultan que ese acto sea expresión del amor sexual. Es más, Scheler está persuadido de que la concepción del acto sexual como acción expresiva es la única que permite restituir al acto sexual la dignidad metafísica de la que ha sido despojado por la cultura occidental moderna. Esta dignidad estriba en que el acto sexual está llamado a colaborar eficazmente con la tendencia axiológica ascendente que anima a la vida cósmica en su conjunto (Alleben), pero sobre todo en que la vida cósmica es un atributo esencial de Dios como fundamento metafísico del universo (cf. GW 7, 136).

Que el acto sexual ha de ser entendido como colaboración del hombre con la divinidad y que por tanto no puede ser banalizado ni reducido a instrumento de intereses egoístas, lo ponen de manifiesto las reflexiones de Scheler acerca del origen individual del hombre. De

impregnaba visiblemente la primera edición del libro, que es de 1913. Esto explica las reiteradas críticas a la "devaluación del amor sexual llevada a cabo por el sacerdote medio" (GW 7, 126; hay expresiones parecidas en pp.124, 125 y 135). Las puyas contra las iglesias cristianas son también frecuentes en las últimas obras de Scheler. 
acuerdo con la antropología scheleriana, la identidad personal de cada ser humano viene dada por su "esencia individual", 25 la cual es creada por Dios y es de naturaleza espiritual. El alma espiritual de cada hombre es, en efecto, "una idea eterna de Dios" (GW 7, 132). Para que esa idea cobre existencia real, necesita encarnarse en un ser vivo. Esto supone que el acto de la voluntad divina por el que es creado cada hombre está sujeto a la condición de colaborar con la tendencia constante de la vida universal a manifestarse como eros, como fuente de la que manan nuevas unidades orgánicas. La vida universal resulta ser, de este modo, la "causa ocasional" del acto por el que Dios, como fundamento espiritual del universo, suscita un nuevo individuo humano al insuflar el alma espiritual en el hombre de carne y hueso, hijo de la vida. Aunque, más que de una única causa ocasional, deberíamos hablar de un encadenamiento de causas, ya que sabemos que el eros universal se manifiesta sucesivamente como amor sexual, como libido y como instinto sexual, para finalmente hacer posible el acto sexual que conduce a la reproducción de la especie.

Pero al hablar de reproducción de la especie traicionamos en alguna medida el pensamiento de Scheler, ya que él no entiende la fecundidad de la vida cósmica como conservación mecánica de lo ya existente, sino como creación, como novedad incesante. El hombre, considerado ahora en su dimensión biológica, no es simplemente obra de sus padres o del conjunto de sus antecesores; su hechura como ser vivo no está unívocamente determinada por la herencia genética, sino que es en cada caso "una manifestación nueva y original de la vida universal misma" (GW 7, 128). Más que de reproducción, deberíamos hablar, muy literalmente, de procreación. El olvido de esta verdad, motivado por el predominio de las concepciones mecanicistas de la vida, explica a juicio de Scheler que en la cultura occidental moderna se registre una lamentable "falta de reverencia ante el milagro siempre nuevo e inaudito del origen del hombre en el nacimiento" (GW 7, 134).

\section{El acto sexual y la unificación afectiva}

En los párrafos precedentes hemos expuesto la reivindicación scheleriana del acto sexual atendiendo a su conexión con la tendencia creadora de la vida universal. Pero la importancia del acto sexual humano es justificada por Scheler también desde una perspectiva gnoseológica. Esta nueva línea argumentativa se apoya, por una parte, en el principio que establece relaciones de fundamentación entre ciertas funciones cognoscitivas de naturaleza emocional; por otra, en la tesis de que hay una conexión clara entre el acto sexual y la más básica de esas funciones, que es la unificación afectiva. Veámoslo.

A juicio de Scheler, la cultura occidental moderna se caracteriza por una fuerte involución de la capacidad humana de unificación afectiva (Einsfühlung) con la naturaleza. Entre las causas principales de este fenómeno destaca la larga vigencia del cristianismo, con su marcada tendencia a la amortización de la naturaleza, ${ }^{26}$ y el progreso imparable de la cien-

25 Véase el magnífico trabajo de P. Fernández Beites, "Sobre la esencia individual”, Diánoia 54 (2005) 33-54.

${ }^{26}$ La gran excepción la constituye el franciscanismo primitivo (cf. GW 7, 97-104). Sobre esta cuestión puede verse L. Rodríguez Duplá, "San Francisco de Asís visto por Max Scheler", Naturaleza y gracia 2-3 (2004) 815-842. 
cia moderna, cuyos planteamientos mecanicistas reducen el fenómeno de la vida a procesos de la materia inerte. De poco han servido las protestas de la filosofía natural romántica: la capacidad de sentir en la propia afectividad el redoble de la vida de otros organismos e incluso el de la vida cósmica en su conjunto presenta signos de atrofia en el hombre occidental. Las consecuencias negativas de esta atrofia están a la vista: por una parte el desconocimiento del valor de la vida no humana y la consiguiente reducción de la naturaleza a objeto de explotación ilimitada por parte de la técnica humana; por otra -y esto es lo que más nos interesa ahora- el empobrecimiento general de la vida afectiva del hombre. ${ }^{27}$

En el estudio dedicado a los fenómenos de simpatía y amor, Scheler no sólo distingue $\mathrm{y}$ analiza las principales variantes de estos sentimientos, sino que sostiene que entre ellas se dan relaciones precisas de fundamentación (cf. GW 7, 105-111). Por ejemplo, no puedo compadecer a otra persona a menos que tenga noticia del dolor que ella siente: mi compasión (Mitgefühl) aparece aquí claramente fundada en la previa captación emocional (Nachfühlen) del dolor ajeno. Pues bien, Scheler sostiene que la forma de simpatía más básica de todas, aquella que condiciona la posibilidad de las demás variantes de la simpatía y el amor, es precisamente la unificación afectiva con la vida cósmica (kosmovitale Einsfühlung). Esta es la razón por la que, al atrofiarse en el hombre occidental moderno el órgano de la unificación afectiva, disminuye forzosamente su capacidad para la simpatía y el amor:

Si desaparece para un individuo o para toda una época cultural la unificación afectiva cosmovital, que indos y griegos habían desarrollado con gran unilateralidad; o si se piensa que ella no es una "genuina y verdadera" fuente de conocimiento metafísico respecto de ciertos aspectos del universo en sí mismo subsistente, los cuales sólo así pueden ser captados; si más bien se la considera superada en su sentido y valor cognitivo por la ciencia o por el cristianismo o por el humanitarismo, con ello se cercena a la vez la raíz original y la fuente nutricia de todas las formas "superiores" de la vida emocional simpatética. (GW 7, 112)

Dado que el retroceso de la capacidad para la unificación afectiva se traduce en penuria emocional y cierra vías insustituibles de conocimiento metafísico, se impone revitalizar esa función afectiva básica. Para ello es preciso indagar el modo como se desarrolla en el hombre la unificación afectiva cosmovital. A juicio de Scheler, la activación primera de esta facultad en el hombre no tiende puentes hacia organismos de otras especies, sino que tiene lugar precisamente entre seres humanos en tanto que unidades vitales. Sólo después se desarrolla en el hombre la capacidad de unificación afectiva con el resto de la naturaleza:

La puerta de acceso a la unificación afectiva con la vida cósmica es la vida cósmica allí donde más cercana y afín le es al ser humano: en el otro ser humano. A quien nunca haya conocido la embriaguez dionisíaca de la unificación afectiva entre ser humano y ser humano [...], también le estará cerrado para siempre el aspecto dinámico-vital de la naturaleza (de la natura naturans, por

\footnotetext{
27 Ante esta situación poco halagüeña, Scheler reaccionará reclamando la búsqueda de un nuevo equilibrio (Ausgleich) entre el ethos occidental y el oriental: el primero aportaría las formas del amor espiritual que sólo son posibles allí donde se ha conocido la categoría de persona; el segundo contribuiría con las formas de unificación afectiva, que gozan de plena vigencia en culturas como las de la India.
} 
contraposición a la natura naturata, única de la que se ocupan la ciencia natural y el saber que conoce la naturaleza por imágenes). (GW 7, 116)

Demos un paso más. En su estudio sobre la simpatía, Scheler distingue múltiples formas de unificación afectiva entre seres humanos, como la identificación de la masa con el líder y de los hombres-masa entre sí, la hipnosis duradera, el sado-masoquismo, la "infección" en sentido freudiano, la fusión recíproca que se da en el acto sexual amoroso o ciertos aspectos de la relación afectiva entre la madre y el niño (cf. GW 7, 29-44). Pero al defender que la unificación afectiva entre seres humanos es la puerta de acceso a la unificación afectiva con la vida cósmica en su conjunto (y la condición del desarrollo de muchas otras formas superiores de la afectividad), Scheler no piensa indistintamente en cualquiera de los fenómenos mencionados, sino sólo en uno: el fenómeno de fusión vital que experimentan los amantes en el acto sexual. Éste es, a su juicio, "el único caso normal de unificación afectiva recíproca con la vida universal" (GW 7, 117). En la embriaguez del acto sexual amoroso, se produce la desconexión de la dimensión personal de los amantes, y es justamente esta disolución extática de su individualidad la que permite su inmersión conjunta en la corriente de la vida cósmica. ${ }^{28}$ Este fenómeno único constituye la base principal de la metafísica vitalista presupuesta por las orgías y misterios báquicos, la prostitución sagrada y tantas otras manifestaciones de las religiones antiguas mediante las cuales los iniciados buscaban la comunión con la naturaleza divinizada. Sin embargo, Scheler está lejos de ver en estos hechos un mero síntoma de primitivismo. Antes bien, el acto sexual representa, también para el hombre moderno, "la puerta de acceso a toda unificación afectiva con el cosmos" $(\mathrm{GW} 7,117)$ y por tanto la condición de posibilidad de toda genuina metafísica de la vida. Scheler se muestra tajante al respecto:

A quien por necia mojigatería o por algún otro motivo desconozca que en el acto sexual amoroso se abre para el hombre civilizado, no un conocimiento, pero sí una fuente material para un posible conocimiento -el cual es de naturaleza metafísica- [...], a quien desconozca que en el acto sexual como vivencia reside la llave natural para toda unificación afectiva cosmovital, a ése le negaría yo la necesaria seriedad que merece esta cuestión (GW 7, 117s.)

\section{Balance y nuevas perspectivas}

Es difícil imaginar una reivindicación más decidida de la importancia metafísica del acto sexual. Con todo, cabe preguntarse $-\mathrm{y}$ no necesariamente por mojigatería- si Scheler no ha llevado demasiado lejos su tesis. Como veremos enseguida, las dudas principales se refieren a la condición de fundamento de todos los fenómenos de simpatía y amor que, según hemos visto, se atribuye aquí a la unificación afectiva, y más en particular a la unificación afectiva recíproca que se produce con ocasión del acto sexual.

\footnotetext{
28 En cambio, en las formas espirituales del amor no se da esta experiencia de unificación o fusión de los amantes, sino que se conserva siempre la distancia entre los sujetos personales. Esto vale tanto para las distintas formas del amor y la amistad como para la genuina experiencia mística.
} 
En el libro Esencia y formas de la simpatía, Scheler enuncia las siguientes "leyes de fundamentación de la simpatía":

a) la unificación afectiva (Einsfühlung) funda el hacerse cargo emocional (Nachfühlen);

b) el hacerse cargo emocional funda la simpatía en sentido estricto (Mitgefühl);

c) la simpatía en sentido estricto funda la filantropía humanitarista;

d) la filantropía funda el amor personal a los hombres y a Dios.

Está claro que si se pudiera mostrar que estos cuatro principios expresan auténticas leyes de esencia, quedaría probado que el hecho de la unificación afectiva condiciona la posibilidad de las demás formas de simpatía y amor. Pero lo cierto es que la exposición de Scheler no resulta del todo convincente. Por de pronto, es dudoso que el sentimiento filantrópico sea condición del amor personal, siendo así que ese sentimiento se refiere al conjunto de la humanidad considerada en su dimensión vital, mientras que el amor personal es de naturaleza espiritual y se refiere a individuos en tanto que tales. Parecería más lógico afirmar que el amor espiritual posee una fuente propia, independiente de toda experiencia vital. ${ }^{29}$ Esto resulta especialmente patente en el caso del amor a Dios, tal como lo concibe el teísmo suscrito por Scheler en De lo eterno en el hombre. Para el teísmo, Dios es un ser personal que transciende al mundo y que, por tanto, no puede ser confundido con una realidad orgánica, ni siquiera con el conjunto de la naturaleza. De hecho, el propio Scheler emplea a menudo el adjetivo "acosmístico" para caracterizar el amor a Dios como ser personal, subrayando de este modo que esta suerte de amor es ajena a los sentimientos que nos abren a la dimensión vital del universo físico.

Podría replicarse que esta objeción, aun siendo importante en sí misma, no afecta a la sustancia del argumento de Scheler que veníamos considerando. Después de todo, nuestra crítica se refería únicamente a la última de las "leyes de fundamentación" antes enunciadas. Las otras tres leyes seguirían en pie y ofrecerían una base suficiente para justificar la tesis de Scheler, sólo que ahora formulada de una forma menos ambiciosa. Pues si fuera verdad, primero, que la unificación afectiva es el fundamento último de toda otra forma de simpatía vital y, segundo, que existe una conexión esencial entre la unificación afectiva y el acto sexual, entonces quedaría probado que al acto sexual le corresponde una función decisiva en el orden del conocimiento metafísico. Para que la tesis de Scheler fuera completamente exacta, bastaría con restringir su alcance: el acto sexual sería la puerta de acceso a la metafísica de la vida. La metafísica del espíritu, en cambio, habría de contar con fuentes de conocimiento propias.

En realidad, tampoco esta versión matizada del argumento de Scheler resulta convincente. Su punto débil estriba, no en la idea de que la unificación afectiva es el fundamento último de la simpatía vital, sino en el modo como se concibe la relación entre esa vivencia básica y el acto sexual. Hemos visto afirmar a Scheler que el acto sexual es nada menos que "la puerta de acceso a toda unificación afectiva con el cosmos" (GW 7, 117). Si esto fuera verdad, su tesis quedaría demostrada. Pero precisamente esta afirmación está muy lejos de ser evidente, e incluso está en conflicto con otras afirmaciones de nuestro filósofo.

${ }^{29}$ Cuál sea esa fuente, o dicho de otra manera, de qué modo comparece la persona individual ante la mirada amorosa, es algo que Scheler no llega a explicar con claridad . Cf. mi trabajo citado en n.3. 
Debe recordarse que, en su minucioso análisis de las formas de la simpatía, Scheler distingue múltiples variantes de la unificación afectiva, pero nunca aporta datos descriptivos que justifiquen su sorprendente afirmación posterior de que sólo la unificación afectiva recíproca, propia del acto sexual, nos pone en contacto emocional con la vida cósmica. Y no es extraño que no lo haga. Precisamente uno de los principios capitales de la "biología pura" elaborada por Scheler es el principio de la unidad de la vida. Todos los incontables organismos del universo participan de la vida cósmica (Alleben), que es única. Según esto, toda experiencia de simpatía vital -por ejemplo, la compasión que siento por un animal heridotiende un puente entre el ser vivo que la experimenta y la vida cósmica. Quien cruza ese puente en actitud reflexiva, está haciendo metafísica de la vida, y ello con independencia de si ha conocido alguna vez la embriaguez de la unificación afectiva recíproca que se da en el acto sexual.

La idea de que el acto sexual es "la llave natural para toda unificación afectiva cosmovital" (GW 7, 117s.) es quizá demasiado extravagante para merecer que nos demoremos en ella. Pero mencionemos al menos que el propio Scheler la ha refutado anticipadamente al insistir a menudo en que el niño posee en general una capacidad para la unificación afectiva mucho más desarrollada que el adulto. Dado que sería arbitrario y contrario a los hechos sostener que la capacidad de unificación afectiva propia de la infancia no se refiere a la vida cósmica en su conjunto, hemos de concluir que la sensibilidad metafísica del niño es mayor que la del adulto, pese a que, debido a su corta edad, no haya conocido la experiencia del acto sexual.

En todo caso, a la hora de hacer balance conviene no perder de vista el alcance limitado de nuestra crítica. Las consideraciones precedentes han mostrado que Scheler ha exagerado la importancia que corresponde al acto sexual en el orden del conocimiento metafísico, pero no afectan al conjunto de la doctrina sobre el amor y el instinto sexual reconstruida en este trabajo. Antes bien, dicha doctrina ha ganado en verosimilitud en la medida en que, mediante una lectura transversal de los textos relevantes, se ha puesto de manifiesto la gran coherencia interna del ambicioso planteamiento de Scheler. Este resultado es importante por cuanto contradice una imagen estereotipada del gran pensador. A menudo se ha sostenido que Scheler es un autor poco sistemático, fecundo en atisbos geniales pero incapaz de integrarlos en una visión unitaria de la realidad. Pero esta idea es, en realidad, puro prejuicio. La lectura atenta de las obras de este autor revela que, pese a las apariencias, su pensamiento tiene un marcado carácter sistemático.

Hemos podido comprobar, en efecto, que la compleja teoría de la sexualidad elaborada por Scheler se inserta de manera coherente en la concepción apriórica de la vida propuesta por este autor. ${ }^{30}$ Recordemos que, de acuerdo con la "biología pura" scheleriana, el eros es la verdadera "esencia demónica" de la vida (GW 7, 133). El eros tiene carácter creador por cuanto aspira constantemente a suscitar realidades orgánicas cada vez más valiosas. En las especies animales que presentan diferenciación de sexos, el eros se manifiesta como amor vital que guía el emparejamiento con vistas a la mejora de la especie. En esta perspectiva, el instinto sexual no es, en realidad, sino un instrumento del que se sirve el amor vital para alcanzar sus metas. No es cuestión de volver aquí sobre los pormenores de este plantea-

30 Me permito remitir nuevamente a mi trabajo "Las ideas biológicas de Max Scheler", Daimon 7 (2012) 97-115. 
miento. Pero debemos dejar constancia de que la discusión de la teoría scheleriana reconstruida en las páginas precedentes no puede atender exclusivamente a los fenómenos de la sexualidad humana, sino que ha de tomar en consideración sus múltiples implicaciones sistemáticas, es decir, ha de ser en realidad una discusión del conjunto de la filosofía de Scheler.

A un resultado semejante se llega al considerar el modo como Scheler moviliza su propia teoría de los sentimientos vitales a la hora de caracterizar el amor sexual. Hemos comprobado, en particular, que el sutil análisis fenomenológico del apetito (entendido como sentimiento que capta el valor nutritivo de los alimentos) y de su relación con el hambre (vivencia de naturaleza tendencial) arroja luz sobre la relación entre el amor vital y el instinto sexual. Por otra parte, el tratamiento de la unificación afectiva, que también desempeña una función central en el planteamiento expuesto, se apoya en la doctrina presentada en una de las más importantes obras de Scheler, Esencia y formas de la simpatía. Todo ello refuerza la impresión de que existe una fuerte cohesión interna entre las numerosas piezas teóricas elaboradas por Scheler en el período intermedio de su actividad filosófica.

Pasando ahora de la perspectiva sistemática a la evolutiva, cabe recordar que los últimos años de la vida de Scheler están marcados por un profundo cambio en su posición metafísica, que le llevó distanciarse del teísmo personalista de inspiración cristiana y a reemplazarlo por una suerte de panteísmo evolutivo en el que es patente la influencia de Spinoza y, más aún, de Eduard von Hartmann. Mucho se ha discutido sobre las razones últimas de este viraje en la posición fundamental de Scheler. Sin duda, abordar este complicado problema desbordaría los límites de nuestro trabajo. Pero señalemos al menos que la exploración de la teoría scheleriana del amor vital y el instinto sexual ha identificado algunos elementos que, aun sin llegar a hacer inevitable el mencionado giro metafísico, lo anticipan en alguna medida. Pensemos, por ejemplo, en la doctrina acerca del origen del individuo humano expuesta al final de nuestro quinto apartado. Según vimos, en la concepción de cada ser humano concurren la pujanza de la vida universal, como principio "demónico" creador (GW 7, 132s.), y la voluntad divina, como principio "espiritual” responsable de la condición personal del nuevo hombre. La unidad última de ambos principios viene dada por el hecho de que también la vida cósmica es, como también se indicó, un atributo de la divinidad. Las afinidades panteístas de este intento de superación del dualismo metafísico están a la vista.

La dualidad de impulso (Drang) y espíritu (Geist) - que son, según la metafísica última de Scheler, los dos atributos de la divinidad conocidos por el hombre- es la formulación última de la distinción entre la esfera vital y la personal, con la que siempre había contado la antropología scheleriana. Una novedad fundamental de esta nueva formulación es la conocida tesis de la "impotencia del espíritu" (Ohnmacht des Geistes), según la cual el espíritu no posee una fuente propia de energía que le permita activarse, sino que ha de tomarla del impulso. ${ }^{31}$ En la nueva concepción, la persona, como centro activo, ya no es vista como una realidad de orden puramente espiritual, sino como el lugar de máxima compenetración del espíritu y el impulso.

31 Esta tesis es defendida por Scheler de manera explícita y consecuente a partir de 1924. En la obra Problemas de una sociología del saber se lee: "El espíritu como tal [...] no tiene en sí mismo -originalmente y de suyo- ni rastro de "energía' o 'eficacia"” (GW 8, 21). 
Es evidente que este cambio tan profundo en la metafísica de Scheler había de conducir a importantes modificaciones en su teoría del amor. La temprana muerte del filósofo, acaecida cuando trabajaba en la redacción de una antropología filosófica acorde con su nueva posición metafísica, le impidió formularlas de manera precisa. Pero en su legado póstumo se han conservado algunos textos importantes que permiten una reconstrucción tentativa. ${ }^{32}$ En ellos Scheler utiliza los términos "Eros" y "Agape" para referirse a las dos formas fundamentales del amor. Podría parecer a primera vista que estos términos equivalen a las expresiones "amor vital" y "amor espiritual", utilizadas por Scheler hasta entonces. Pero esta impresión inicial es engañosa, habida cuenta de que a estas alturas, habiendo suscrito el principio de la impotencia del espíritu, el filósofo ya no creía posible un "amor acosmístico", es decir, un amor puramente espiritual capaz de activarse de manera independiente. Antes bien, tanto el eros como el ágape son concebidos ahora como resultados de la colaboración entre los dos principios metafísicos fundamentales, el impulso y el espíritu.

El eros es impulso que se ha vuelto lúcido, "vidente" (GW 12, 236), merced al espíritu que lo guía y configura. El ágape es espíritu que, gracias a la energía que le presta el impulso, puede superar su natural impotencia y desplegar su acción creadora. El eros hace posible el desarrollo de la ciencia y de la técnica humanas; no porque de él proceda la inteligencia, que también se da en el animal, sino porque el eros libera la inteligencia de su atadura al entorno vital inmediato, condicionado por las pulsiones instintivas, y la eleva a un nuevo nivel de abstracción. El conocimiento de las esencias, en cambio, es privativo del ágape, y con ese conocimiento la posibilidad de la creación de cultura según ideas y valores que no provienen de la necesidad natural. En la perspectiva del último Scheler, ambas formas del amor están llamadas a colaborar: no sólo porque el eros proporciona al ágape la energía de que éste carece y que, debido a su origen espiritual, no puede tomar directamente del nivel instintivo; sino también porque el eros es la función psíquica que abre por vez primera el ámbito en el que se desplegarán la actividad creadora del ágape.

Como queda dicho, las ideas que acabamos de presentar no llegaron a recibir un tratamiento amplio por parte de Scheler. Habremos de conformarnos por ahora con el anterior bosquejo. Sólo un estudio en profundidad de la metafísica elaborada por Scheler en los últimos años de su vida autorizaría, acaso, a elaborar una hipótesis convincente sobre el desarrollo que estas ideas estaban llamadas a recibir y sobre la función que habrían desempeñado en la antropología filosófica en la que trabajaba cuando le sorprendió la muerte. ${ }^{33}$

\section{Leonardo Rodríguez Duplá}

Dpto. de Filosofía del Derecho, Moral y Política II

Universidad Complutense de Madrid

leonardo.rodriguez.dupla@filos.ucm.es

\footnotetext{
32 El más importante de esos textos del Nachlass scheleriano, publicados póstumamente por M. Frings, es el titulado "Eros" (GW 12, 232-238).

33 Para un interesante ensayo de reconstrucción de la teoría del amor del último Scheler, véase G.Cusinato "Eros und Agape bei Scheler", en: C. Bermes / W. Henckmann / H. Leonardy (Hrsg.), Vernunft und Gefühl. Schelers Phänomenologie des emotionalen Lebens, Würzburg, 2003, pp.93-109.
} 